\title{
Permainan Roda Pelangi sebagai Media untuk Meningkatkan Karakter Fairness Siswa Sekolah Dasar
}

\author{
Nora Yuniar Setyaputri, Yuanita Dwi Krisphianti, Ikke Yuliani Dhian Puspitarini \\ Program Studi Bimbingan dan Konseling, Fakultas Keguruan dan Ilmu Pendidikan, \\ Universitas Nusantara PGRI Kediri, Jl. K.H. Ahmad Dahlan No. 76, Kediri, Jawa Timur, Indonesia 64112 \\ E-mail: setyaputrinora@gmail.com
}

Artikel diterima: 30 Agustus 2018; direvisi: 25 September 2018; disetujui: 26 September 2018

\begin{abstract}
The purpose of this study was to determine the effectiveness of Roda Pelangi game to improve elementary school students' fairness character. The research method was an experiment with a nonequivalent control group design type. The research instruments were: interview guidelines; observation guidelines; and Fairness Character Measurement Scale. The sample were twelve fourth grade students of Permata Ummat Trenggalek Integrated Islamic Elementary School that was chosen through purposive sampling. The significance score obtained based on data analysis using independent sample t-test was $0.047<0.05$. The result showed Roda Pelangi game can improve elementary school students' fairness character. Based on these results, it recommended: school counselor can use Roda Pelangi game in the guidance and counseling service process, especially to improve elementary school students' fairness character; further researchers can use Roda Pelangi game to examine other variables and at other school levels using other research designs such as true experiment or guidance and counseling action research.
\end{abstract}

Keywords: media; roda pelangi game; fairness

\begin{abstract}
Abstrak: Tujuan dari penelitian ini adalah untuk mengetahui keefektifan permainan Roda Pelangi untuk meningkatkan karakter fairness siswa Sekolah Dasar (SD). Metode penelitian yang digunakan adalah eksperimen dengan jenis nonequivalent control group design. Instrumen penelitian yang digunakan yaitu pedoman wawancara; pedoman observasi; dan Skala Pengukuran Karakter Fairness. Sampel berjumlah dua belas siswa kelas IV SD Islam Terpadu (IT) Permata Ummat Trenggalek yang dipilih secara purposif. Skor signifikansi yang diperoleh berdasarkan analisis data menggunakan independent sample t-test adalah $0,047<0,05$. Hasil menunjukkan bahwa permainan Roda Pelangi dapat meningkatkan karakter fairness siswa SD. Berdasarkan hasil tersebut maka disarankan: guru Bimbingan dan Konseling (BK) dapat menggunakan media permainan Roda Pelangi dalam proses layanan BK, khususnya untuk meningkatkan karakter fairness siswa SD; peneliti selanjutnya dapat menggunakan media permainan Roda Pelangi untuk meneliti variabel lain dan pada jenjang sekolah lainnya menggunakan desain penelitian lain seperti true experiment maupun penelitian tindakan BK.
\end{abstract}

Kata kunci: media; permainan roda pelangi; fairness

Sikap adalah salah satu bagian penting dari kompetensi utama yang menjadi standar kompetensi lulusan dalam pendidikan, dimana karakter adalah bagian dari komponen sikap tersebut. Di dalam sikap, terdapat beberapa karakter yang harus dikembangkan, karena keberhasilan seseorang dalam aspek pribadi; karier; sosial maupun belajar sangat dipengaruhi oleh karakter (Arumsari, 2018). Salah satu jenis karakter tersebut adalah fairness. Fairness diwujudkan dengan perilaku individu yang memperlakukan individu lain tanpa membeda-bedakan. Fairness memiliki arti tidak suka memanfaatkan kelemahan orang lain untuk keuntungan pribadi, menghargai kesetaraan antar 
individu, bermain sesuai peran atau taat pada aturan yang berlaku, bersikap transparan serta adil terhadap sesama (Josephson, 2006). Fairness merupakan salah satu bagian dari tujuh karakter kebajikan yang harus dimiliki dan dikembangkan dalam diri seorang anak (Borba, 2001). Fairness merupakan salah satu jenis dari kekuatan karakter kebajikan (justice) yang sangat diperlukan untuk mewujudkan kehidupan sosial dan masyarakat yang sehat dengan interaksi antar individu dan kelompok yang terjalin selaras (Peterson \& Seligman, 2004). Individu yang memiliki karakter fairness akan berperilaku adil dan menggunakan prinsip pluralisme kepada sesama tanpa mempertimbangkan intuisionisme (Soetoprawiro, 2010). Berdasarkan pendapat para ahli tersebut, dapat diketahui bahwa karakter ini sangat perlu dimiliki oleh setiap individu dan pembinaannya perlu dilakukan sedini mungkin.

Karakter yang berkualitas perlu dibina sejak usia dini agar anak terbiasa berperilaku positif (Prasetyo, 2011), oleh karena itu pengembangan karakter perlu dilakukan sedini mungkin agar pada usia dewasa dapat memiliki perilaku yang positif (Lerner, 2018). Mengapa anak SD tingkat atas yang dipilih sebagai subjek sasaran? Hal ini karena anak usia tujuh sampai dua belas tahun berada pada tahap operasional konkret (Piaget, 1959). Pada usia tujuh sampai dua belas tahun ini seorang anak belajar untuk mengembangkan kemampuan bernalar logis dan memahami konservasi, namun mereka hanya dapat menggunakan kedua kemampuan ini dalam menghadapi situasi yang sudah dikenal. Piaget (1959) melakukan sebuah penelitian tentang anak-anak melalui permainan kelereng dimana penelitian ini berkaitan dengan karakter fairness pada anak.

Penelitian Piaget kemudian dikembangkan oleh Kohlberg (1981) yang mengidentifikasikan tiga tingkat perkembangan moral dimana setiap tingkat terdapat dua tahapan. Pada tingkat precoventional tahap dua menunjukkan bahwa anak yang termasuk dalam tahap ini adalah anak yang berusia delapan sampai dua belas tahun. Di Indonesia usia delapan sampai dua belas tahun merupakan usia siswa SD kelas atas yakni kelas empat sampai kelas enam. Pada tahap ini, siswa akan belajar untuk mengetahui dan memahami pentingnya saling berbagi; memahami dan mengembangkan fairness; serta menghargai sesama; akan tetapi siswa belum bisa belajar untuk memahami sebuah loyalitas dan keadilan. Siswa akan berpikir secara operasional konkret, dan egosentris mereka secara perlahanlahan akan menghilang. Pada usia delapan sampai dua belas tahun, siswa mulai bisa menghargai sudut pandang dan pendapat orang lain yang berbeda dengan dirinya.

Lingkungan sosial memiliki peran untuk memengaruhi kemampuan kognitif siswa seperti: perhatian; persepsi; pola pikir dan perilaku siswa seperti: kerjasama; saling membantu; berbagi; dan berkontribusi (Adler, 1964). Sebuah kelas merupakan tempat dimana siswa bisa membangun lingkungan sosial yang bermanfaat bagi dirinya (Adler, 1964). Di dalam kelas, siswa bisa berhubungan dengan orang lain dan membuat kondisi yang nantinya siswa akan mendapatkan pemahaman mengenai tujuan dan konsekuensi dari perilaku mereka. Siswa yang berada pada kelas enam jenjang pendidikan dasar dan yang sudah memiliki kemampuan berpikir operasional konkret hendaknya sudah bisa memahami lingkungan sosialnya untuk mengembangkan karakter fairness mereka. Karakter fairness dapat diajarkan kepada siswa yang berada pada jenjang SD (Sawatzki \& Sullivan, 2018).

Kurang dimilikinya karakter fairness oleh siswa SD ditandai dengan minimnya sikap sama rata; adil atau menganggap orang lain sama yang ada pada diri siswa SD (Krisphianti, Hidayah, \& Irtadji, 2016). Wujud lain dari kurang dimilikinya karakter fairness tersebut antara lain memilihmilih teman; tidak menggunakan atribut sekolah; suka memanfaatkan teman dengan menyuruh; dan tidak mau mendengarkan orang lain (Krisphianti et al., 2016). Berdasarkan pernyataan tersebut dapat ditarik makna bahwa saat ini sering kali dijumpai seorang anak menjadi ketua gang pembully di sekolah karena merasa bahwa dirinya lebih kuat dari teman-temannya, merasa paling kaya atau merasa lebih pandai dari teman-temannya yang lain. Jika ditarik benang merah dari fenomena ini, anak-anak tersebut belum dapat membangun dan mengembangkan karakter fairness di dalam diri mereka. 
Kurang dimilikinya karakter fairness tersebut juga tercermin pada perilaku siswa SD IT Permata Ummat Kabupaten Trenggalek. Perilaku yang ditunjukkan seperti: memilih-milih teman; berbohong untuk keuntungan dirinya sendiri; mengejek teman; serta berlagak seperti bos yang menyuruhnyuruh temannya. Fenomena ini diperoleh berdasarkan hasil pengamatan peneliti yang dilakukan pada bulan Juni tahun 2017. Munculnya perilaku tersebut menimbulkan permasalahan tersendiri di sekolah. Ada beberapa siswa yang merasa: terkucil atau tidak populer; takut untuk bersosialisasi; muncul persaingan yang tidak sehat; serta pertengkaran yang sering kali membuat guru-gurunya repot. Karakter fairness yang tidak berkembang dengan baik berdampak kepada perkembangan pribadi dan sosial siswa di masa depan (Krisphianti et al., 2016).

Ditinjau dari perkembangan pribadinya, siswa dapat menjadi individu yang menang sendiri dan senang berbohong demi keselamatan diri sendiri, sedangkan secara sosial siswa dapat menjadi individu yang sulit mendapatkan teman; sulit beradaptasi pada lingkungan pergaulan; dikucilkan di antara teman; dan menjadi individu yang tidak memedulikan lingkungan sekitar (Krisphianti et al., 2016). Maka karakter fairness ini sangat perlu untuk dikembangkan pada diri siswa SD, khususnya di SD IT Permata Ummat Kabupaten Trenggalek. Sebagai sarana untuk mengembangkan karakter fairness dan untuk mengurangi kebosanan pada anak, perlu dipilih sebuah media yang sesuai dan memenuhi unsur kebaruan seperti media permainan Roda Pelangi.

Media permainan Roda Pelangi dikembangkan tahun 2015 oleh Setyaputri, Ramli, \& MappiareAT (2015). Permainan Roda Pelangi merupakan sebuah media yang mudah untuk digunakan, dapat diadaptasikan untuk meningkatkan beberapa variabel seperti self-esteem, dan tidak memerlukan biaya yang mahal untuk membuatnya (Setyaputri, 2016). Permainan Roda Pelangi perlu untuk diuji dengan subjek yang lebih luas dengan variasi cerita yang ada dalam komponen media sesuai dengan variabel yang akan dikembangkan (Setyaputri et al., 2015). Dapat diartikan bahwa media permainan ini dapat diadaptasi untuk meningkatkan karakter fairness siswa SD. Kecocokan pemilihan permainan sebagai sarana/ media untuk meningkatkan karakter fairness siswa SD mengacu pada pendapat Geldard \& Geldard (2009). Permainan dinilai paling cocok untuk menjadi media bagi kelompok usia anak SD (enam sampai sepuluh tahun), praremaja (sebelas sampai tiga belas tahun) dan remaja (empat belas sampai tujuh belas tahun) (Geldard \& Geldard, 2009).

Beberapa komponen dari media permainan Roda Pelangi adalah: (1) papan tembak; (2) alat pembidik; (3) amplop warna; dan (4) panduan permainan Roda Pelangi untuk Guru BK (Setyaputri et al., 2015). Amplop warna berisi cerita yang disusun berdasarkan empat indikator karakter fairness. Indikator fairness menurut Josephson (2006) adalah: (1) menghargai kesetaraan antar individu yakni individu yang berbuat adil akan memandang seluruh individu lain secara objektif berdasarkan keragaman dan keunikan dari masing-masing makhluk hidup; (2) bermain sesuai dengan peran yang dimaksud adalah taat dan patuh akan peraturan yang berlaku di masyarakat; (3) tidak suka memanfaatkan kelemahan orang lain untuk kepentingan pribadi adalah individu yang berbuat adil, ketika berbuat salah akan segera mengakui secara sukarela dan meminta maaf atas perbuatan yang telah dia lakukan, individu akan segera memperbaiki kesalahan yang dilakukan dan tidak menggunakan kelemahan orang lain untuk menutupi perbuatan salah yang telah dilakukan; (4) bersikap transparan dan adil terhadap sesama adalah individu yang independent ketika mengambil sebuah keputusan bukan didasarkan dari pilih kasih terhadap pihak tertentu dan prasangka pribadi, melainkan didasarkan pada sebuah informasi yang sesuai fakta.

Berdasarkan kajian penelitian terdahulu, karakterfairness siswa SD ini dapat ditingkatkan melalui penggunaan media wayang topeng Malang (Krisphianti et al., 2016). Pada saat memanfaatkan media wayang topeng Malang, Guru BK menceritakan cerita rakyat Panji Asmorobangun kepada siswa dengan menggunakan topeng Malang, kemudian siswa diminta untuk menyimak dan menganalisis. Dalam permainan Roda Pelangi, siswa dilibatkan pada seluruh kegiatan permainan mulai dari kegiatan membidik papan tembak, mengambil cerita yang ada di dalam amplop warna, membaca dan mempraktikkan cerita tersebut. Salah satu contohnya adalah ketika ada cerita yang mengharuskan siswa untuk bermain peran (memerankan klenting kuning, klenting ijo, klenting abang, klenting 
biru) serta refleksi dan evaluasi. Dalam proses semua kegiatan tersebut, siswa berkolaborasi penuh dengan Guru BK. Dengan melibatkan langsung siswa dalam kegiatan bermain akan lebih memenuhi unsur interaktivitas karena lebih berpusat pada siswa.

Cerita yang disusun dalam permainan Roda Pelangi tidak hanya memasukkan cerita rakyat saja, namun juga cerita yang mencerminkan perilaku sehari-hari siswa SD yang belum ataupun yang telah memiliki karakter fairness. Cerita yang disusun di Permainan Roda Pelangi merupakan contoh-contoh perilaku anak seusia SD agar lebih mudah dipahami karena terdapat unsur kesetaraan. Permainan Roda Pelangi memanfaatkan bentuk dan model yang baru agar siswa tidak bosan dalam mengikuti layanan BK di sekolah.

Mengacu pada hasil studi pendahuluan yang telah dipaparkan mengenai pentingnya pengembangan karakter fairness bagi siswa SD dan studi literatur mengenai pemilihan media yang sesuai untuk mewadai/sarana pengembangan karakter tersebut, maka dilakukan penelitian untuk mengetahui keefektifan permainan roda pelangi sebagai media untuk meningkatkan karakter fairness siswa SD.

\section{METODE}

Metode penelitian yang digunakan adalah experiment dengan jenis nonequivalent control group design. Pada penelitian ini, variabel independent adalah permainan Roda Pelangi dan variabel dependent adalah karakter fairness siswa SD. Secara khusus penjelasan dari tahap-tahap dalam penelitian ini disajikan pada tabel 1. Instrumen yang digunakan adalah: pedoman observasi; pedoman wawancara; dan Skala Pengukuran Karakter Fairness yang terdiri dari 62 pernyataan, dimana pernyataan tersebut telah valid dan reliabel.

Proses validasi dilakukan pada 109 siswa kelas enam dari empat sekolah dasar Islam yang berbeda di Kota Malang. Butir sebelum validasi berjumlah 73 butir dan setelah proses validasi berjumlah 62 butir. Reliabilitas butir sebesar 0,899. Koefisien reliabilitas sebesar 0,899 mempunyai arti bahwa keajegan dari skala ini tergolong tinggi dan tentunya dapat dipakai untuk mengukur karakter fairness. Hal ini karena koefisien reliabilitas sebesar 0,70 atau lebih pada umumnya dianggap adekuat untuk maksud-maksud penelitian (Groth-Marnat, 2009).

Penelitian dilaksanakan di SD IT Permata Ummat Kabupaten Trenggalek. Populasi penelitian adalah seluruh siswa kelas empat yang berjumlah 86 siswa dengan rincian: 31 siswa kelas 4A; 29 siswa kelas 4B; dan 26 siswa kelas 4C. Hasil pretest disajikan pada tabel 2. Teknik pemilihan sampel yang dipakai adalah purposive sampling. Kriteria pemilihan sampel yaitu siswa SD kelas atas yang mempunyai tingkat karakter fairness kurang dan sangat kurang. Adapun empat kriteria interpretasi hasil dari perhitungan skala ini yaitu: (1) Sangat Tinggi dengan rentang skor 202-248; (2) Tinggi dengan rentang skor 190-201; (3) Kurang dengan rentang skor 180-189; dan (4) Sangat Kurang dengan rentang skor $62-179$.

Setelah Skala Pengukuran Karakter Fairness disebarkan kepada populasi, ditemukan sepuluh siswa yang mempunyai tingkat karakter fairness sangat kurang dan dua siswa yang mempunyai tingkat karakter fairness kurang. Kedua belas siswa tersebut dijadikan sampel penelitian, yang kemudian dibagi menjadi dua kelompok. Enam siswa masuk kelompok eksperimen dan enam siswa masuk kelompok kontrol. Sebelum kegiatan eksperimen dilanjutkan, peneliti melakukan uji beda untuk mengetahui bahwa kedua kelompok ini memiliki kondisi atau kemampuan yang sama.

Uji hipotesis dilakukan menggunakan Independent Sample t-test apabila diperoleh sebaran data normal, namun apabila ditemukan sebaran data tidak normal, maka perhitungan yang digunakan yaitu U Mann Whitney dengan bantuan program SPSS IBM Statistic 20.0. Hipotesis nol ditolak jika diperoleh signifikansi kurang dari 0,05 dan sebaliknya. Data-data yang bersifat non angka/verbal yakni berupa pendapat siswa akan dideskripsikan dan digunakan sebagai bahan pendukung. Bahan pendukung untuk menarik simpulan dari deskripsi tersebut, sehingga memberikan gambaran yang jelas terhadap aspek yang dinilai. 
Tabel 1 Tahapan Penelitian

\begin{tabular}{|c|c|c|}
\hline No. & Kelompok Eksperimen & Kelompok Kontrol \\
\hline 1 & $\begin{array}{l}\text { Pelaksanaan pretest (seluruh siswa kelas empat) } \\
\text { menggunakan Skala Pengukuran Karakter Fair- } \\
\text { ness, ditemukan dua belas siswa yang tingkat } \\
\text { karakter fairnessnya masih perlu ditingkatkan, } \\
\text { siswa kemudian dibagi menjadi dua kelompok. } \\
\text { enam siswa pada kelompok eksperimen dan enam } \\
\text { siswa pada kelompok kontrol (tahap pembentukan } \\
\text { kelompok). }\end{array}$ & $\begin{array}{l}\text { Pelaksanaan pretest (seluruh siswa kelas empat) } \\
\text { menggunakan Skala Pengukuran Karakter Fair- } \\
\text { ness, ditemukan dua belas siswa yang tingkat } \\
\text { karakter fairnessnya masih perlu ditingkatkan, } \\
\text { siswa kemudian dibagi menjadi dua kelompok. } \\
\text { enam siswa pada kelompok eksperimen dan enam } \\
\text { siswa pada kelompok kontrol (tahap pembentukan } \\
\text { kelompok). }\end{array}$ \\
\hline 2 & $\begin{array}{l}\text { Pemberian layanan bimbingan kelompok menggu- } \\
\text { nakan permainan Roda Pelangi kepada enam } \\
\text { siswa sebagai anggota kelompok eksperimen. } \\
\text { Kegiatan pada tahap ini adalah: } \\
\text { a. Pertemuan pertama (tahap awal dan tahap } \\
\text { transisi). } \\
\text { b. Pertemuan kedua sampai kelima (tahap kerja, } \\
\text { penggunaan permainan Roda Pelangi). } \\
\text { Pada kegiatan ini Guru BK memfasilitasi siswa } \\
\text { agar mereka aktif turut serta dalam kegiatan. } \\
\text { Salah satu siswa diminta secara sukarela untuk } \\
\text { membidik warna di dalam papan Roda Pelangi. } \\
\text { Kemudian mengambil cerita pada amplop warna } \\
\text { yang warnanya sesuai dengan bidikan tersebut. } \\
\text { Cerita yang disusun dalam amplop warna disusun } \\
\text { berdasarkan keempat indikator karakter fairness. } \\
\text { Salah satu siswa diminta untuk membaca, sedang- } \\
\text { kan yang lain memerhatikan cerita tersebut. } \\
\text { Setelah proses atensi tersebut dilalui, Guru BK } \\
\text { meminta kepada siswa untuk mengolah isi cerita } \\
\text { dalam pikiran mereka dan mendiskusikannya. } \\
\text { Dalam proses diskusi, Guru BK mengajak siswa } \\
\text { untuk mengetahui kekurangan dan kelebihan dari } \\
\text { isi cerita kemudian merefleksikan pada perilaku } \\
\text { yang pernah siswa lakukan pada kehidupan nyata. } \\
\text { Setelah proses refleksi, Guru BK mengajak siswa } \\
\text { untuk merevisi perilaku kurang tepat yang pernah } \\
\text { mereka lakukan dengan perilaku baru yang lebih } \\
\text { adaptif dan berkomitmen untuk melakukan } \\
\text { perilaku baru tersebut. Proses ini dilakukan } \\
\text { selama empat pertemuan dengan maksud untuk } \\
\text { membahas keempat indikator karakter fairness } \\
\text { tersebut. Setiap pertemuan hanya digunakan } \\
\text { untuk membahas satu indikator. Instrumen yang } \\
\text { dipakai adalah pedoman observasi. }\end{array}$ & $\begin{array}{l}\text { Pemberian layanan bimbingan kelompok tanpa } \\
\text { menggunakan permainan Roda Pelangi kepada } \\
\text { enam siswa sebagai anggota kelompok kontrol. } \\
\text { Kegiatan pada tahap ini adalah: } \\
\text { a. Pertemuan pertama (tahap awal dan tahap } \\
\text { transisi). } \\
\text { b. Pertemuan kedua sampai kelima (tahap kerja). } \\
\text { Pada kegiatan ini Guru BK meminta siswa untuk } \\
\text { membaca materi yang disusun berdasarkan indi- } \\
\text { kator karakter fairness. Setelah proses menyimak } \\
\text { materi selesai, Guru BK memberikan kesempatan } \\
\text { untuk sesi tanya jawab. Setelah sesi tanya jawab } \\
\text { Guru BK menjelaskan maksud dari materi tersebut } \\
\text { dan mendiskusikannya dengan siswa. Setelah } \\
\text { proses diskusi selesai, Guru BK mengajak siswa } \\
\text { menyimpulkan materi bersama-sama. Kegiatan } \\
\text { ini berlangsung selama empat pertemuan untuk } \\
\text { membahas keempat karakter fairness. Setiap } \\
\text { pertemuan hanya digunakan untuk membahas } \\
\text { satu indikator. Instrumen yang dipakai adalah } \\
\text { pedoman observasi. }\end{array}$ \\
\hline 3 & $\begin{array}{l}\text { Pelaksanaan posttest kepada enam siswa anggota } \\
\text { kelompok eksperimen serta menutup kegiatan } \\
\text { (pertemuan keenam (tahap akhir)). Instrumen } \\
\text { yang digunakan adalah pedoman wawancara dan } \\
\text { Skala Pengukuran Karakter Fairness. }\end{array}$ & $\begin{array}{l}\text { Pelaksanaan posttest kepada enam siswa anggota } \\
\text { kelompok kontrol serta menutup kegiatan (per- } \\
\text { temuan keenam (tahap akhir)). Instrumen yang } \\
\text { digunakan adalah pedoman wawancara dan Skala } \\
\text { Pengukuran Karakter Fairness. }\end{array}$ \\
\hline
\end{tabular}


Tabel 2 Hasil Analisis Skor Sampel Penelitian

\begin{tabular}{ccccc}
\hline No & Kelas & Inisial & Skor & Kriteria \\
\hline 1 & IV A & K1 & 183 & Kurang \\
2 & IV A & K2 & 173 & Sangat Kurang \\
3 & IV B & K3 & 171 & Sangat Kurang \\
4 & IV B & K4 & 177 & Sangat Kurang \\
5 & IV B & K5 & 173 & Sangat Kurang \\
6 & IV B & K6 & 179 & Sangat Kurang \\
7 & IV B & K7 & 176 & Sangat Kurang \\
8 & IV B & K8 & 178 & Sangat Kurang \\
9 & IV C & K9 & 179 & Sangat Kurang \\
10 & IV C & K10 & 162 & Sangat Kurang \\
11 & IV C & K11 & 160 & Sangat Kurang \\
12 & IV C & K12 & 181 & Kurang \\
\hline
\end{tabular}

\section{HASIL}

Hasil analisis pada sebaran skor pretest diperoleh bahwa data berdistribusi normal, yaitu dengan skor signifikansi 0,852 maka independent sample t test dipilih untuk melakukan uji beda. Uji beda dilakukan untuk mengetahui apakah kelompok eksperimen dan kontrol memiliki kemampuan yang sama atau tingkat karakter fairness yang sama. Diperoleh skor signifikansi sebesar 0,444 dimana signifikansi ini lebih besar dari 0,05. Dapat dimaknai bahwa tidak terdapat perbedaan kemampuan antara kelompok eksperimen dan kelompok kontrol. Kedua kelompok ini mempunyai tingkat karakter fairness yang sama rendahnya.

Setelah kelompok eksperimen diberi perlakuan kegiatan bimbingan menggunakan permainan Roda Pelangi dan kelompok kontrol diberi perlakuan kegiatan bimbingan tanpa menggunakan permainan Roda Pelangi, siswa diminta untuk mengisi Skala Pengukuran Karakter Fairness (posttest). Berdasarkan analisis dari gain score kelompok eksperimen dan kelompok kontrol diperoleh skor rata-rata kelompok eksperimen sebesar 41,5, sedangkan kelompok kontrol sebesar 21,33. Hasil uji hipotesis menyatakan bahwa signifikansi yang diperoleh sebesar 0,047 dimana skor signifikansi ini lebih kecil dari 0,05. Dapat dimaknai bahwa terdapat perbedaan tingkat karakter fairness antara kelompok eksperimen dan kelompok kontrol, dengan kata lain hipotesis alternatif diterima dan hipotesis nol ditolak.

Kelompok yang diintervensi menggunakan permainan Roda Pelangi terbukti memiliki tingkat karakter fairness lebih tinggi dibanding kelompok yang tidak diintervensi menggunakan permainan Roda Pelangi. Rekapitulasi perhitungan gain score kedua kelompok disajikan pada tabel 3.

Dalam proses intervensi, diperoleh data non angka dari siswa kelompok eksperimen yang menyebutkan bahwa mereka senang diajak bermain karena menurut mereka permainan ini seru, hal ini didapatkan dari ungkapan subjek K6 dan subjek K4 yang mengatakan "seru-seruuu enek panah-panahane barang" (seru ada permainan panahnya). Siswa kelompok eksperimen juga mengatakan baru kali ini melihat permainan tersebut. Pada awalnya siswa kelompok eksperimen mengira yang dibidik oleh panah adalah pusat dari Roda Pelangi, namun setelah dijelaskan mereka baru mengetahui bahwa yang dibidik adalah warna-warna yang terdapat pada Roda Pelangi. Warnawarna Roda Pelangi menurut siswa kelompok eksperimen bagus, hal ini didapatkan dari beberapa siswa yang mengatakan "warnane apik yo cah?" (warnanya bagus ya teman-teman?) dan yang lain menyahut "ho'oh apik" (iya, bagus).

Beberapa siswa kelompok eksperimen juga mengatakan bahwa cerita yang ada dalam amplop cinta (siswa kelompok eksperimen menyebut amplop warna pada permainan Roda Pelangi sebagai amplop cinta) mirip dengan perilaku yang mereka alami sendiri, seperti: sering terlambat sekolah 
Tabel 3 Rekapitulasi Gain Score Kelompok Eksperimen dan Kontrol

\begin{tabular}{|c|c|c|c|c|c|c|c|c|c|c|c|}
\hline \multicolumn{12}{|c|}{ Gain Score Eksperimen dan Kontrol } \\
\hline \multicolumn{5}{|c|}{ Eksperimen } & \multirow{2}{*}{\multicolumn{2}{|c|}{$\begin{array}{c}\text { Inisial } \\
\text { Sampel }\end{array}$}} & \multicolumn{5}{|c|}{ Kontrol } \\
\hline $\begin{array}{l}\text { Pre- } \\
\text { test }\end{array}$ & Kriteria & $\begin{array}{c}\text { Post- } \\
\text { test }\end{array}$ & Kriteria & Gain & & & $\begin{array}{l}\text { Pre- } \\
\text { test }\end{array}$ & Kriteria & $\begin{array}{c}\text { Post- } \\
\text { test }\end{array}$ & Kriteria & Gain \\
\hline 183 & Kurang & 203 & $\begin{array}{l}\text { Sangat } \\
\text { Tinggi }\end{array}$ & 20 & K1 & K7 & 176 & $\begin{array}{l}\text { Sangat } \\
\text { Kurang }\end{array}$ & 187 & Kurang & 11 \\
\hline 173 & $\begin{array}{l}\text { Sangat } \\
\text { Kurang }\end{array}$ & 239 & $\begin{array}{l}\text { Sangat } \\
\text { Tinggi }\end{array}$ & 66 & $\mathrm{~K} 2$ & K8 & 178 & $\begin{array}{l}\text { Sangat } \\
\text { Kurang }\end{array}$ & 202 & $\begin{array}{l}\text { Sangat } \\
\text { Tinggi }\end{array}$ & 24 \\
\hline 171 & $\begin{array}{l}\text { Sangat } \\
\text { Kurang }\end{array}$ & 198 & Tinggi & 27 & $\mathrm{~K} 3$ & K9 & 179 & $\begin{array}{l}\text { Sangat } \\
\text { Kurang }\end{array}$ & 190 & Tinggi & 11 \\
\hline 177 & $\begin{array}{l}\text { Sangat } \\
\text { Kurang }\end{array}$ & 205 & $\begin{array}{l}\text { Sangat } \\
\text { Tinggi }\end{array}$ & 28 & K4 & K10 & 162 & $\begin{array}{l}\text { Sangat } \\
\text { Kurang }\end{array}$ & 192 & Tinggi & 30 \\
\hline 173 & $\begin{array}{l}\text { Sangat } \\
\text { Kurang }\end{array}$ & 220 & $\begin{array}{l}\text { Sangat } \\
\text { Tinggi }\end{array}$ & 47 & K5 & K11 & 160 & $\begin{array}{l}\text { Sangat } \\
\text { Kurang }\end{array}$ & 195 & Tinggi & 35 \\
\hline \multirow[t]{2}{*}{179} & $\begin{array}{l}\text { Sangat } \\
\text { Kurang }\end{array}$ & 240 & $\begin{array}{l}\text { Sangat } \\
\text { Tinggi }\end{array}$ & 61 & K6 & K12 & 181 & Kurang & 198 & Tinggi & 17 \\
\hline & & & & $\begin{array}{c}\text { Mean= } \\
41,50\end{array}$ & & & & & & & $\begin{array}{c}\text { Mean= } \\
41,50\end{array}$ \\
\hline
\end{tabular}

dan kena denda Rp 2.000,00 per harinya (perilaku ini dilakukan oleh subjek K6); sering lupa mengembalikan Alquran pada tempatnya ketika baru selesai mengaji di masjid sekolah (perilaku ini dilakukan oleh subjek K2, subjek K4, subjek K6); sering dikeluarkan dari kelas oleh ustazahnya karena berbicara sendiri ketika berdoa bersama di kelas (perilaku ini dilakukan oleh subjek K4); ada yang mengejek temannya karena bau mulut (perilaku ini dilakukan oleh subjek K1-K6), ada yang merasa barang kepunyaannya selalu lebih bagus dari temannya (hal ini dilakukan oleh subjek K1K6); malas mengerjakan pekerjaan rumah dan memilih untuk mencontek teman ketika di sekolah (dilakukan oleh subjek K4 dan subjek K6). Data-data ini diperoleh dari proses diskusi bersama siswa kelompok eksperimen ketika mereka diberi pemahaman bahwa perilaku yang ada pada cerita dan yang sering mereka lakukan tersebut kurang tepat dan memiliki dampak negatif. Siswa dapat saling bertukar pikiran dan pendapat dengan teman yang lain apakah perilaku mereka tersebut baik atau tidak. Hal ini dilakukan setelah membaca cerita yang ada pada amplop warna setelah salah satu dari mereka membidik Roda Pelangi, kemudian pemimpin dalam kelompok meminta satu per satu anggota kelompok untuk mengkritisi cerita tersebut dan kemudian merefleksikan pada diri mereka sendiri.

\section{PEMBAHASAN}

Eratnya hubungan antara BK dengan komunikasi (Dehlendorf, Krajewski, \& Borrero, 2014) merupakan salah satu alasan keterlibatan media dalam pelaksanaan layanan BK. Komunikasi adalah dasar semua interaksi manusia yang di dalamnya terdapat proses penyampaian pesan/informasi dari komunikator kepada penerima pesan atau komunikan serta adanya balikan dari penerima pesan tersebut (Johnson \& Johnson, 1991; Nursalim, 2013). BK dikatakan berhubungan erat dengan proses komunikasi karena di dalam proses pelaksanaan layanan BK terjadi proses penyampaian pesan BK dari Guru BK (komunikator) kepada siswa (komunikan). Salah satu ciri tercapainya komunikasi dalam proses bimbingan yang baik adalah terjadinya persamaan penafsiran pesan BK yang telah disampaikan guru BK dan siswa. Tercapainya komunikasi yang baik antara guru BK dan siswa 
salah satunya dipengaruhi oleh media yang digunakan dalam proses penyampaian pesan tersebut (Alhadi, Supriyanto, \& Dina, 2016; Setyaputri et al., 2015). Seperti halnya pada penelitian ini, telah dibuktikan bahwa media permainan Roda Pelangi efektif meningkatkan karakter fairness siswa SD.

Merujuk pada hasil analisis data angka dapat diketahui bahwa rata-rata gain score kelompok eksperimen lebih tinggi dari kelompok kontrol, yaitu 41,50: 21,33. Skor signifikasi sebesar 0,047 dimana skor signifikansi ini lebih kecil dari 0,05 . Hal ini merupakan data yang mendukung pendapat pada paragraf sebelumnya mengenai keefektifan penggunaan media pada proses layanan BK. Kelompok yang dalam proses pelaksanaan bimbingan kelompoknya menggunakan media permainan Roda Pelangi terbukti tingkat karakter fairnessnya lebih tinggi daripada kelompok yang dalam proses layanan bimbingan kelompoknya tidak menggunakan media permainan Roda Pelangi.

Berdasarkan analisis data non angka dapat diketahui bahwa siswa tertarik pada warna Roda Pelangi dan bentuk Roda Pelangi. Ketertarikan siswa mengenai warna dalam Roda Pelangi dikarenakan pemilihan warna yang mencolok dan bentuk yang baru dapat membangkitkan minat dan perhatian siswa (Hasebrook, 2016; Nursalim, 2013). Kebaruan media merupakan salah satu aspek yang akan menarik perhatian siswa (Setyaputri, 2016; Setyaputri et al., 2015; Türkay, 2016), dan Media Roda Pelangi memiliki kebaruan tersebut. Keefektifan penggunaan media permainan Roda Pelangi dalam proses layanan BK khususnya untuk meningkatkan karakter fairness siswa SD ini mendukung pendapat Setyaputri (2018) mengenai fungsi media BK dalam proses layanan BK yaitu: (1) memperjelas pesan BK; (2) mengatasi keterbatasan ruang, waktu dan daya indera; (3) meningkatkan minat siswa; (4) memberikan perangsang yang sama, mempersamakan pengalaman dan menimbulkan persepsi yang sama; (5) menghidupkan saraf motorik dan dapat melibatkan kelima indera siswa seperti penglihatan, pendengaran, peraba, perasa, dan penciuman; (6) mengurangi kebosanan siswa atau dapat dikatakan bahwa proses layanan BK dapat lebih menarik; (7) menambah interaktivitas proses layanan BK; (8) meningkatkan kualitas layanan BK; (9) meningkatkan sikap positif siswa; serta (10) meningkatkan kreativitas baik dari sisi Guru BK maupun siswa.

Karakter fairness kelompok kontrol yang diintervensi dengan kegiatan bimbingan lewat pemberian bahan bacaan dan berdiskusi tanpa permainan Roda Pelangi juga mengalami peningkatan. Namun, peningkatan tingkat karakter fairness kelompok kontrol masih dibawah kelompok eksperimen. Hal ini dapat dikarenakan adanya faktor kebosanan dari siswa kelompok kontrol karena metode yang digunakan sudah sering mereka jumpai. Metode pembelajaran yang terus diulang dan membosankan memang dapat membuat siswa bosan dan menurunkan motivasi (Lai, Peng, Chen, \& Lin, 2013; Sillaots, 2014; Wijaya, 2017; YaJuan, 2011). Pada kelompok eksperimen, kebosanan siswa saat mengikuti layanan bimbingan dapat tereduksi. Kebosanan ini dapat tereduksi karena mulai dari awal sampai akhir siswa diwajibkan aktif untuk terlibat. Keterlibatan siswa dalam kegiatan di kelas dapat meningkatkan hasil belajar siswa (Mork, 2011; Munir, Sutarno, \& Aisyah, 2018). Keaktifkan siswa kelompok eksperimen adalah dengan membidik papan tembak; mengambil cerita yang ada dalam amplop warna; membacakan cerita; mempraktikkan isi cerita; sampai pada proses refleksi dan evaluasi siswa. Hal ini dimaksudkan untuk memenuhi unsur interativitas, karena media permainan Roda Pelangi merupakan salah satu jenis media interaktif (Setyaputri et al., 2015).

Antusiasme siswa sangat nampak saat permainan berlangsung, misalnya saat diminta sukarela siapa yang ingin membidik papan tembak, mayoritas siswa angkat tangan; kemudian saat diajak bermain peran guru tidak kesulitan untuk membujuk siswa dan ketika diminta untuk mengutarakan pendapat serta pengalamannya siswa secara spontan mengutarakan hal tersebut. Selain bentuk yang tergolong baru untuk mereka, cerita yang disajikan dalam amplop warna sesuai dengan halhal yang pernah mereka lakukan. Kesesuaian ini dikarenakan pada saat penyusunan cerita tersebut disesuaikan dengan indikator dan hasil pengamatan mengenai perilaku yang berkaitan dengan kurang dimilikinya karakter fairness tersebut. Model yang ada dalam cerita tersebut juga disesuaikan dengan tingkat usia anak SD agar mudah dipahami, walaupun umur tidak memberi pengaruh yang cukup kuat pada efektifitas modelling (Oliva, del Mar Aragón, \& Cuesta, 2015; Stoffers \& Van der Heijden, 2018). Perbedaan cara intervensi inilah yang menyebabkan perbedaan pada hasil kelompok eksperimen dan kontrol. 
Kemenarikan proses layanan bimbingan dengan menggunakan media seperti permainan Roda Pelangi ini terbukti dapat meningkatkan antusiasme siswa, mereduksi kebosanan, serta meningkatkan pemahaman terhadap materi yang diberikan sehingga tingkat karakter fairness mereka lebih tinggi dari kelompok siswa yang tidak diintervensi menggunakan permainan ini. Di sisi lain, kegiatan bermain merupakan suatu kegiatan yang menyenangkan dan melekat pada diri siswa SD (Landreth, Ray, \& Bratton, 2009; Wang, 2018). Bermain adalah aktifitas yang dipilih sendiri oleh anak karena menyenangkan, bukan karena memperoleh hadiah atau pujian, bermain juga merupakan alat utama untuk mencapai pertumbuhannya, dan sebagai medium anak mencobakan diri bukan saja hanya dalam fantasinya tetapi dilakukan secara nyata (Andriani, 2012). Keberhasilan dalam pelaksanaan permainan Roda Pelangi untuk meningkatkan karakter fairness siswa SD ini tidak hanya ditentukan oleh kualitas media permainan Roda Pelangi, tetapi juga tidak terlepas dari beberapa faktor penunjang seperti kondisi dan situasi siswa saat pelaksanaan permainan dan kondisi guru BK. Pernyataan tersebut dapat didasarkan pada sistem yang ada dalam BK, untuk tercapainya suatu tujuan BK tentunya dipengaruhi oleh masing-masing komponen yang ada dalam sistem dan media hanya merupakan salah satu komponen dari sistem tersebut.

\section{SIMPULAN}

Berdasarkan pada proses dan hasil analisis data penelitian, permainan Roda Pelangi yang memiliki komponen: papan tembak; amplop warna; alat pembidik; dan panduan permainan Roda Pelangi, terbukti efektif meningkatkan karakter fairness siswa SD. Saran diajukan kepada Guru BK agar menggunakan media permainan Roda Pelangi dalam proses layanan BK, khususnya untuk meningkatkan karakter fairness siswa SD. Peneliti selanjutnya disarankan dapat menggunakan media permainan Roda Pelangi untuk meneliti variabel lain dan pada jenjang sekolah lainnya menggunakan desain penelitian lain seperti true experiment maupun penelitian tindakan BK.

\section{DAFTAR RUJUKAN}

Adler, A. (1964). Social Interest: A Challenge to Mankind (Vol. 108). Capricorn Books New York.

Alhadi, S., Supriyanto, A., \& Dina, D. A. M. (2016). Media in Guidance and Counseling Services: A Tool and Innovation for School Counselor. SCHOULID: Indonesian Journal of School Counseling, 1(1), 6-11. https://doi.org/10.23916/schoulid.v1i1.35.6-11

Andriani, T. (2012). Permainan Tradisional dalam Membentuk Karakter Anak Usia Dini. Sosial Budaya, 9(1), 121-136.

Arumsari, C. (2018). Kekuatan Karakter dan Kebajikan dalam Bimbingan dan Konseling. Journal of Innovative Counseling: Theory, Practice, and Research, 2(1), 1-5.

Borba, M. (2001). Building Moral Intelligence: The Seven Essential Virtues that Teach Kids to Do The Right Thing. Jossey-Bass San Francisco.

Dehlendorf, C., Krajewski, C., \& Borrero, S. (2014). Contraceptive Counseling: Best Practices to Ensure Quality Communication and Enable Effective Contraceptive Use. Clinical Obstetrics and Gynecology, 57(4), 659-673. https://doi.org/10.1097/GRF.0000000000000059

Geldard, K., \& Geldard, D. (2009). Counselling Children : A Practical Introduction. London: Sage Publications.

Groth-Marnat, G. (2009). Handbook of Psychological Assessment. John Wiley \& Sons.

Hasebrook, J. (2016). Cognitive Design for Learning: Cognition and Emotion in the Design Process. Dalam International Association for Development of the Information Society, Makalah disajikan pada International Association for Development of the Information Society (IADIS) International Conference on Cognition and Exploratory Learning in the Digital Age (CE (hal. 203-209). ERIC. 
Johnson, D. W., \& Johnson, F. P. (1991). Joining Together: Group Theory and Group Skills. PrenticeHall, Inc.

Josephson, M. (2006). Making Ethical Decisions: The Six Pillars of Character. Diambil 30 Mei 2016, dari www.josephsoninstitude.com

Kohlberg, L. (1981). The Meaning and Meaurement of Moral Development. Worcester, MA: Clark University Press.

Krisphianti, Y. D., Hidayah, N., \& Irtadji, M. (2016). Efektivitas Teknik Storytelling Menggunakan Media Wayang Topeng Malang untuk Meningkatkan Karakter Fairness Siswa Sekolah Dasar. PSIKOPEDAGOGIA Jurnal Bimbingan dan Konseling, 5(1), 17-23.

Lai, C.-H., Peng, W.-J., Chen, W.-H., \& Lin, R.-M. (2013). The Effect of Learning Community for Game-Based English Learning. Dalam Workshop Proceedings of the 21st International Conference on Computers in Education, ICCE 2013 (hal. 19-27).

Landreth, G. L., Ray, D. C., \& Bratton, S. C. (2009). Play Therapy in Elementary Schools. Psychology in The SCHOOLS, 46(3), 281-289.

Lerner, R. M. (2018). Character Development Among Youth: Linking Lives in Time and Place. International Journal of Behavioral Development, 42(2), 267-277.

Mork, S. M. (2011). An Interactive Learning Environment Designed to Increase The Possibilities for Learning and Communicating about Radioactivity. Interactive Learning Environments, 19(2), 163-177. https://doi.org/10.1080/10494820802651060

Munir, M., Sutarno, H., \& Aisyah, N. S. (2018). The Development of Interactive Multimedia Based on Auditory, Intellectually, Repetition in Repetition Algorithm Learning to Increase Learning Outcome. Dalam Journal of Physics: Conference Series (Vol. 1013). https://doi. org/10.1088/1742-6596/1013/1/012102

Nursalim, M. (2013). Pengembangan Media Bimbingan dan Konseling. Jakarta: PT Indeks.

Oliva, J. M., del Mar Aragón, M., \& Cuesta, J. (2015). The Competence of Modelling in Learning Chemical Change: A Study with Secondary School Students. International Journal of Science and Mathematics Education, 13(4), 751-791.

Peterson, C., \& Seligman, M. E. P. (2004). Character Strengths and Virtues: A Handbook and Classification. Oxford University Press.

Piaget, J. (1959). The Language and Thought of The Child. London: Routledge \& Kegan Paul.

Prasetyo, N. (2011). Membangun Karakter Anak Usia Dini. Kementerian Pendidikan Nasional.

Sawatzki, C., \& Sullivan, P. (2018). Shopping for Shoes: Teaching Students to Apply and Interpret Mathematics in the Real World. International Journal of Science and Mathematics Education, 16(7), 1355-1373. https://doi.org/10.1007/s10763-017-9833-3

Setyaputri, N. Y. (2016). Media Permainan "Roda Pelangi" sebagai Alternatif Pilihan Media Bimbingan dan Konseling di Sekolah. Dalam Seminar Nasional Peran Bimbingan dan Konseling dalam Pendidikan Karakter Menyongsong Generasi Emas Indonesia. Surabaya: Universitas Negeri Surabaya.

Setyaputri, N. Y. (2018). Urgensi Pemanfaatan Media BK dalam Proses Layanan Bimbingan dan Konseling. Dalam Seminar Pendidikan dan Pengajaran 2. Universitas Nusantara PGRI Kediri.

Setyaputri, N. Y., Ramli, M., \& Mappiare-AT, A. (2015). Pengembangan Media Permainan "Roda Pelangi" untuk Meningkatkan Efikasi Diri Siswa SMP dalam Menghadapi Ujian. Bimbingan dan Konseling: Jurnal Teori dan Praktik, 28(1), 38-46.

Sillaots, M. (2014). Achieving Flow through Gamification: A Study on Re-designing Research Methods Courses. Dalam Proceedings of the European Conference on Games-based Learning (Vol. 2, hal. 538-545). 
Soetoprawiro, K. (2010). Keadilan sebagai Keadilan. Pro Justitia, 28(2), 229-256.

Stoffers, J. M. M., \& Van der Heijden, B. I. J. M. (2018). An Innovative Work Behaviour-enhancing Employability Model Moderated by Age. European Journal of Training and Development, 42(1/2), 143-163.

Türkay, S. (2016). The Effects of Whiteboard Animations on Retention and Subjective Experiences When Learning Advanced Physics Topics. Computers and Education, 98, 102-114. https://doi. org/10.1016/j.compedu.2016.03.004

Wang, L. (2018). All Work, All Play: Harnessing Play-based Learning in Ethiopia and Liberia to Create Lifelong Learners. Childhood Education, 94(5), 4-13.

Wijaya, H. (2017). Practice-led Project As A Creative Method to Enhance Theoretical Knowledge in Art and Design Education. Advanced Science Letters, 23(2), 726-729. https://doi.org/10.1166/ as 1.2017 .7443

YaJuan, W. (2011). Design and Research of Multimedia Teaching in Sports Technique Class of University. Dalam ICCSE 2011 - 6th International Conference on Computer Science and Education, Final Program and Proceedings (hal. 736-739). https://doi.org/10.1109/ ICCSE.2011.6028742 